\section{(A) Check for updates}

Cite this: Food Funct., 2020, 11, 3751

\title{
Correction: Efficacy of proprietary Lactobacillus casei for anti-tuberculosis associated gastrointestinal adverse reactions in adult patients: a randomized, open-label, dose-response trial
}

\author{
Song Lin, ${ }^{a, b}$ Shanliang Zhao, ${ }^{c}$ Jiahong Liu, ${ }^{d}$ Jianwen Zhang, ${ }^{a}$ Chao Zhang, ${ }^{a}$

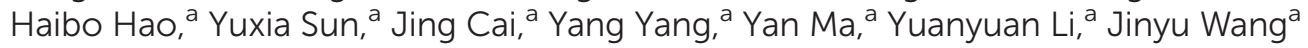 \\ and Aiguo $\mathrm{Ma}^{* a}$
}

DOI: $10.1039 / \mathrm{dOfo} 90017 f$

Correction for 'Efficacy of proprietary Lactobacillus casei for anti-tuberculosis associated gastrointestinal adverse reactions in adult patients: a randomized, open-label, dose-response trial' by Song Lin et al.,

rsc.li/food-function Food Funct., 2020, 11, 370-377.

The authors regret that the L. casei preparation used was not produced by Yakult Honsha Co., Ltd (Tokyo, Japan) as indicated in the original manuscript. The L. casei preparation, which was a commercial probiotic fermented milk drink manufactured by Yakult (China) Corporation, does not contain fructose.

Consequently, sections of the text in the manuscript should be adjusted according to this change, and these are detailed below.

The sentences in the "Randomization and intervention" section on page 371 beginning "The $L$. casei preparation was produced by..." should be correctly given as "A commercial probiotic fermented milk drink manufactured by Yakult (China) Corporation was used for this study (L. casei preparation). It contains the L. casei strain Shirota, filtered water, skimmed milk, and glucose."

The sentence in the "Acknowledgements" section on page 376 beginning "Yakult Honsha Co., Ltd provided..." should be correctly given as "A commercial probiotic fermented milk drink manufactured by Yakult (China) Corporation was used for this study (L. casei preparation). However Yakult (China) Corporation did not exert any influence on the study design, data collection, and analysis as well as writing of the manuscript."

The Royal Society of Chemistry apologises for these errors and any consequent inconvenience to authors and readers.

\footnotetext{
${ }^{a}$ The College of Public Health, Qingdao University, 38 Dengzhou Road, Qingdao, 266021 Shandong province, China. E-mail: magfood@qdu.edu.cn; Fax: +86 532 83812434; Tel: +8653282991518

${ }^{b}$ Department of Medical Epidemiology and Biostatistics, Karolinska Institutet, Nobels Väg 12A, 17177 Stockholm, Sweden

${ }^{c}$ Linyi People's Hospital East Branch, 27 Jiefang East Road, Lanshan District of Linyi, 276000 Shandong province, China

${ }^{d}$ The Qingdao Central Hospital, 127 Siliu South Road, Qingdao 266000, Shandong province, China
} 